\section{Knowledge of skull base anatomy and surgical implications of human sacrifice among pre-Columbian Mesoamerican cultures}

TO THE EDITOR AND READERSHIP: On behalf of all authors, I respectfully request retraction of our article, "Knowledge of skull base anatomy and surgical implications of human sacrifice among pre-Columbian Mesoamerican cultures" (Neurosurg Focus 33(2):E1, 2012) in response to complaints from Ximena Chávez Balderas, MPhil, MA, Researcher with the Templo Mayor Project, and Lic. Maria del Perpetuo Socorro Villarreal Escárcega, National Coordinator for Legal Affairs at the National Institute of Anthropology and History (INAH).

Ms. Chávez Balderas objects to "unauthorized use of images and contents from [her] published work." At the time of writing, I believed that we had reported her work accurately. I apologize for any errors that were made.

An additional complaint is that we did not obtain proper authorization to reproduce figures in the article, three of which were taken and published by Ms. Chávez Balderas, and which belong to the INAH, and one that was originally published by Prof. Eduardo Matos Moctezuma, Emeritus Professor at the INAH.
On this latter point, we have received a formal request from the INAH that we remove all contents related to the work of Ms. Chávez Balderas and the figures belonging to the INAH. Knowing that these materials are pivotal components of the article, we must request retraction of this paper.

I would like to clarify the fact that the paper was written by my own personal initiative in an attempt to share with the neurosurgical community some of our rich Mesoamerican history. None of my former professors (coauthors) directly participated in drafting the paper, and thus I assume the full responsibility for any mistakes unwittingly made during this process.

I apologize to Ms. Chávez Balderas, the INAH, and its researchers, as well as to the editors and readers of Neurosurgical Focus. The authors appreciate the opportunity to retract this paper.

Raúl López-Serna, MD

Centro de Especialidades Neurológicas, Cancún, Mexico

\section{INCLUDE WHEN CITING}

DOI: 10.3171/2018.5.FOCUS12120r.

CAANS 2018, except where prohibited by US copyright law 